\title{
Research strategies in human behaviour genetics
}

\author{
F VOGEL \\ From Institut für Anthropologie und Humangenetik, University of Heidelberg, Im Neuenheimer Feld 328, \\ D-6900 Heidelberg, Federal Republic of Germany.
}

This paper is based on the third Carter memorial lecture of the Clinical Genetics Society given in April 1986.

SUMMARY Genetic variation influencing normal and abnormal human behaviour has been studied since Francis Galton's work in the second half of the 19th century. However, most of these studies have consisted of biometric analysis of complex phenotypes; the genotype has been treated as a 'black box'. The concepts and analytical tools of modern genetics have rarely been used. In this lecture, some examples are given of approaches combining tools from genetics, cytogenetics, and various fields of neurobiology which might help in the analysis of genetic mechanisms leading, in interaction with the environment, to individual differences in behaviour, mental performance, and susceptibility to mental diseases.

\section{O Carter and the scientific tradition of human behaviour genetics}

Reading through Cedric Carter's Human heredity ${ }^{1}$ in preparation for this lecture, I found, much to my surprise, that 31 of the 257 pages, or about one-eighth of the book, were devoted to the discussion of genetic factors influencing intelligence. Moreover, discussion of mental defects and psychiatric diseases comprised a substantial part of the chapter on 'Common illnesses'. Human heredity was published in 1962. At that time, Carter belonged to the middle generation of human geneticists, the generation that had introduced genetic concepts into medicine, gradually convincing the medical profession that genetics might not only concern a few very rare and exotic monstrosities, but might offer clues for our understanding of diseases in general. But he was conscious of scientific tradition, and the problems of genetic influence on intellectual performance and behaviour (on individual differences in behaviour and performance, to be more precise) had been one of the basic concerns of early human geneticists, right back to Francis Galton's classic work Hereditary talent and character which was published in $1865 .^{2}$

Meanwhile, we have seen enormous progress in basic research, as well as in practical applications of

Received for publication 11 July 1986. Accepted for publication 14 July 1986. genetic concepts and tools in medicine. Refined diagnosis using DNA techniques is helping us in 'secondary prevention' of genetic disease by prenatal diagnosis, and gene therapy, introducing DNA into somatic cells, is just around the corner. ${ }^{3}$ Drawn by the hawser of our modern methods, we have moved away from the questions our scientific forefathers asked. This would be no cause for regret, had these questions become obsolete scientifically or unimportant for our society. This, however, is not at all true. In a world in which traditional values and life patterns are losing influence, and every generation has to cope with an ever increasing number of new problems, answers to the question of how genes influence the function of our brain, the ways in which we experience the world around us, and behave in it, are more urgent than ever before. Hence, it is not surprising that, after human geneticists have lost interest, problems of psychological genetics are now being studied by members of other scientific communities, for example, psychologists and psychiatrists. We can learn from them, but we should not leave the field to them entirely.

\section{The growth of scientific knowledge}

To understand this, let us reflect upon the ways in which scientific knowledge grows. We have learned from historians of science, such as Ludwig Fleck ${ }^{4}$ and Thomas Kuhn, ${ }^{5}$ that our impression from basic text books that scientific knowledge grows regularly 
according to endogenous laws in a rational interplay between theory, appropriate research methods, and accumulating results is, at the least, incomplete. Rather, it grows guided by certain 'paradigms', as $\mathrm{Kuhn}^{5}$ has called them. To quote Kuhn": "These I take to be universally recognized scientific achievements that for a time provide model problems and solutions to a community of practitioners". Meanwhile, this notion has become extremely popular to the point that some are jeering at 'the march of paradigms'. But a notion must not necessarily be wrong only because it is popular.

\section{The paradigms of Mendel and Galton and a research project that does not exist}

According to Kuhn, a paradigm consists of three elements. (1) A piece of scientific work that serves as an "exemplar", suggesting ways in which a certain problem should be approached. (2) A group of scientists who try to explore this approach, expand its applicability, deepen its theoretical basis, and enhance its explanatory power. (3) It should also contain at least the germ of a scientific theory; a successful paradigm will culminate in elaboration of this theory.

For me personally, conceiving the history of human genetics as a contest of two paradigms has explained aspects of historical development that would be difficult to understand otherwise. These two paradigms have been founded by Mendel's report on Versuche über Pflanzenhybriden ${ }^{6}$ and by Galton's study on Hereditary talent and character. ${ }^{2}$ At the centre of Mendel's paradigm, we find the gene concept, which has developed from 1900, when Mendel's laws were rediscovered, right up to our present achievements in molecular genetics. ${ }^{7}$ Mendel's discovery was the germ of a scientific theory which proved to be most fertile, not only for our theoretical understanding of structure and function of genetic material but also for concept, diagnosis, and prevention of disease. ${ }^{\gamma}$ Those of us involved in research are doing most of our daily work within the context of this paradigm. We often forget that a second approach exists, and is still necessary for the solution of several practical problems: the biometric method founded by Francis Galton. In his germinal study of $1865, "$ Galton counted the number of unusually successful men among close relatives, for example, sons or brothers, of unusually successful probands. Finding many more than expected from the hypothesis of independent occurrence, he concluded that individual differences in socially rewarded performance are caused mainly by differences of inherited abilities. Later on, he added measuring to counting, complemented his armoury of methods with the forerunner of Pearson's correlation coefficient, and pointed to twins as a source of valuable information. ${ }^{9}$ Compared with analysis of $-\overrightarrow{0}$ segregation and gene action on Mendelian lines, $\frac{}{0}$ Galtonian methods have the advantage of being $\bar{\omega}$ applicable wherever phenotypes can be counted or $\widehat{\mathbb{D}}$ measured, and this means almost everywhere. Mendelian analysis, on the other hand, seemed to ${ }^{\circ}$ be confined in the beginning to rare anomalies such $\overrightarrow{0}$ as albinism or lobster claw. Carter belonged to $a-$ group of critical observers, mainly in Britain, whow taught us that in genetic analysis of common traits (normal and pathological) we have to satisfyç ourselves with the genetic model of polygenic inheritance, with or without a threshold. ${ }^{10}$ He never $\dot{\omega}$ denied that this is a very rudimentary level of $\vec{N}$ genetic analysis. Application of Mendelian techni- 0 ques, on the other hand, often required definition of phenotypes to be analysed by increasingly sophisti- cated methods, mainly from biochemistry and later 3

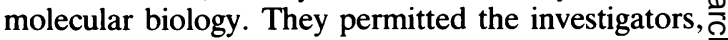
gradually in several intermediate steps, to approach the level of the genes themselves*.

Impressed by the unsurpassed exlanatory power of. $\stackrel{\infty}{-\infty}$ Mendelian theory, we tend to forget that in our dailyo work of genetic counselling, we often fall back on Galtonian approaches, for example, when we use risk figures to make a prognosis for birth defects oro mental disease. We also forget that there is an entire scientific community of scientists who rely almost $\stackrel{2}{\rightarrow}$ completely on Galton's approach and on the methods of 'quantitative genetics' derived from it. These are differential psychologists, especially those? interested in problems such as 'How much of the inter-individual variability in IQ is genetically determined?' It is unnecessary for me to remind you of the heated discussions on this point in which some 3 such as Jensen ${ }^{12}{ }^{13}$ and Eysenck, ${ }^{14}$ hold the viewo that it may be about three-quarters, whereas others, such as Kamin, ${ }^{15}$ even regard a zero contribution as possible.

In order to understand how inappropriate and counterproductive the attempt to answer the question is, assume, for the sake of argument, that you are asked to give a recommendation for possible 0 funding of the following research proposal.

Somebody wants to study the heritability of quan- $\omega$ titative blood haemoglobin levels in the populatione of Tanzania compared with Great Britain. In an elaborate research design, he plans to compare $M Z_{C}^{\mathbb{\Phi}}$ and DZ twins, reared apart and together, and parents with their biological and adopted children, $\frac{0}{0}$ taking into account age, sex, education, and socioeconomic status.

*For the levels of genetic analysis, see Vogel and Motulsky. 
No doubt, this study would lead to the expected hierarchy of correlations and a substantial, but not extremely high, heritability estimate. The research workers would be able to draw a nice path diagram. There would also be a significant difference between the two countries, Britain giving higher values for the mean and a lower variance. As to heritability, I do not dare to predict for which country it would be higher.

I am sure you, as a referee, would turn down this proposal, and with good reasons. You know that the haemoglobin value depends on a number of genetic and environmental factors, such as incidence and prevalence of haemoglobin variants and thalassaemias, iron supply, infestation with intestinal worms, and many others. You would know that all these factors have to be studied in order to gain insight into the biological mechanisms influencing haemoglobin levels. In comparison with these insights, you would regard the global end result of all these influences at the population level, heritability, as relatively uninteresting.

Still this very problem continues to fascinate research workers as well as the general public in the field of intelligence research. The reasons are hardly comprehensible except from the sociological point of view. The paradigm group of research workers in this field has very little, if any, connection with geneticists; they simply have not realised the superior analytical opportunities offered by genetic concepts and methods. Therefore, they do not question the very basis of their approach. They do not see that the question of the basic biological mechanisms influencing mental performance is much more productive, since it stimulates studies that could elicit much more specific answers. ${ }^{11}$

This criticism does not apply to all psychologists working on the intelligence problem. There are now many groups who are studying brain mechanisms of mental performance using various approaches, for example, the number of 'bits' of information to be processed within a given time span, ${ }^{16}$ complex reaction time, ${ }^{17} 18$ evoked EEG potentials, ${ }^{14}$ and others. They try to analyse the problem 'from top to bottom', whereas the geneticist would tend to analyse it 'from bottom to top'. May be they will meet in the middle sometime.

It would be unfair, however, to attribute the failure to recognise the problem only to the deficiencies of scientists. Another important factor is pressure from outside, from the general public. Persons and organisations responsible for education, for the care of the socially maladjusted, mentally retarded, and mentally ill often ask: "To what degree is all this genetically determined?". This is largely because they often hold the mistaken view that whatever has a strong genetic component can be influenced very little by external measures. ${ }^{12}$ Heritability estimates are attempts to answer this question directly. But science, before answering questions from outside, should first reflect on these questions in the light of the present state of its theories and analytical tools. Doing so, scientists will often come to the conclusion that the questions have first to be reformulated before a meaningful answer can be sought. In some fields, such as human behaviour genetics, this process might be too time consuming to satisfy demands from the community at large. We cannot avoid giving preliminary answers to questions that cannot be answered definitely at present, but we should keep in mind the final problem. In my opinion, empirical risk figures for mental diseases to be used in genetic counselling are legitimate preliminary answers to pressing, practical questions, since they may lead to rational decisions by our clients. However, I have difficulties in seeing the point of heritability estimates of IQ tests scores within our 'normal' population. (IQ tests in individual subjects do have a use. They may help, for example, to decide between options for occupational training.)

\section{Principles to be followed in human behaviour genetics}

After all this criticism, how should we proceed properly when studying genetic differences in mental performance and behaviour? At first glance, the answer is simple: we should follow the same principles that have proved to be so successful in other branches of human genetics. In order to turn this general principle into concrete research proposals, let us start with a simplistic and empirical way, using in addition to some very basic genetic principles information available to us from our experience in medical genetics. Let us reconsider first some old and new results and promising approaches in the field of intellectual performance. It is a useful strategy to start with the lower extreme of IQ distribution, since here we can expect to find simpler conditions than in the more 'average' range.

The best known examples for genetic variation in the lower range are the common chromosomal aberration syndromes, such as Down's syndrome or Klinefelter's syndrome and its variants. Here, the negative effect of the genetic anomaly on brain function is obvious. It is also very likely that it is caused by some anomaly in the embryonic development of the brain. Beyond this very general statement, more specific conclusions cannot yet be drawn as few studies have been performed on brain morphology in Down's syndrome and other chromo- 
somal syndromes. Surprisingly small anomalies have been reported; it is possible that groups of cells did not quite reach their predetermined place in the brain during embryonic development compared to normal brains. ${ }^{19}$

In addition to studies using refined histopathological methods, animal studies appear to be most promising in clarifying basic principles. Chromosome 16 of the mouse, for example, is, in part, homologous to the human chromosome 21 . Trisomies can be bred at will from strains with certain Robertsonian translocations. Unfortunately, mice trisomic for chromosome 16 die during embryonic development, but hybrids can be produced by artificial fusion of early embryonic states, and they can then be studied from various points of view ( $W$ Buselmaier, 1986, personal communication).

Another promising opening towards more basic biological mechanisms underlying differences in mental performance is the study of rare hereditary diseases. There are surprisingly many diseases in which an enzyme defect, in addition to a variety of other clinical signs, leads to some disturbance of brain function (table 1). In about one-third of all autosomal recessive conditions classified by McKusick $^{20}$ as 'confirmed', mental retardation, other severe anomalies of the CNS, or epilepsy are regular or at least frequent clinical signs. Obviously, this means that many more metabolic pathways must be normal to secure undisturbed function of our brain than for other organ systems. These

TABLE 1 Number of diseases with mental retardation or seizures or both among autosomal recessives (from McKusick ${ }^{20}$; see also reference 21).

\begin{tabular}{llll}
\hline $\begin{array}{l}\text { Confirmed } \\
\text { autosomal recessive } \\
\text { conditions with } \\
\begin{array}{l}\text { sufficient } \\
\text { information }\end{array}\end{array}$ & $\begin{array}{l}\text { Severe disorders } \\
\text { of CNS as a } \\
\text { clinical sign }\end{array}$ & $\begin{array}{l}\text { Anomalies } \\
\text { of CNS } \\
\text { frequent }\end{array}$ & $\begin{array}{l}\text { Epileptic } \\
\text { seizures } \\
\text { frequent }\end{array}$ \\
\hline 547 & 166 & 32 & 29 \\
\hline
\end{tabular}

metabolic pathways need not necessarily affect cells $\stackrel{+}{\rightarrow}$ of the nervous system directly, as in the lipid storage diseases. Indirect effects, for example, by toxico metabolites, are also possible, as seen in흐 phenylketonuria. ${ }^{21}$ This example shows that some- $-\overline{\bar{c}}$. times studies on the extreme conditions offered by such metabolic diseases may not be very informative for our understanding of variability in the normal or ${ }^{\text {s }}$ near-normal range. A cynical observer could liken it $\vec{\circ}$ to the attempt of a small boy to explore the way $\mathrm{a} \overrightarrow{\vec{\omega}}$ wrist watch works by hitting it with a hammer. Still,, such studies, if interpreted critically, may point to the metabolic pathways primarily important foro normal brain function.

\section{Studies on clinically 'normal' heterozygotes}

There is another line of analysis which is pursuedo surprisingly rarely, despite the fact that it is straight- forward genetically, a logical consequence of ours genetical and hiochemical knowledge, and pub $\frac{2}{2}$ lished results point to a significant influence. This is the study of heterozygotes. As a rule, activity of the $\overrightarrow{0}$ deficient enzyme in heterozygotes is about half of the normal in recessive metabolic diseases. It would be an obvious conclusion that this is sufficient undero average conditions but might fail when this pathways is put under stress. Indeed, slight differences compared with normal controls, in aspects of intellectual ability or personality have been de- 0 scribed, for example, for phenylketonuria, various $\overrightarrow{\vec{O}}$ lipid storage diseases, and microcephaly (table 3 2) ${ }^{22-24}$ The most data are available for phenyl ketonuria. Some of these studies may be criticised? for not fulfilling the criteria of epidemiology, but on the whole they strongly point to an influence on the phenotype, at least in some cases. For example $\frac{5}{3}$ stress situations, such as influenza with high fever or pregnancy, may lead to transitory increases of blood? phenylalanine levels. Interestingly enough, some mutations leading to hereditary metabolic diseases? apparently influence not only intellectual perform- $\rightarrow$

TABLE 2 Results indicating functional deviations in heterozygotes for autosomal recessive diseases (for details and ${ }^{\circ}$ references see $\operatorname{Vogel}^{22}$.

\begin{tabular}{ll}
\hline Disease & Functional deviations reported \\
\hline Phenylketonuria & $\begin{array}{l}\text { Greater increase of blood phenylalanine during febrile infections and pregnancy. EEG signs of increased cerebral } \\
\text { irritability. Reduction of test intelligence, especially verbal ability by a few IQ points. Correlations between intellectual } \\
\text { performance and blood phenylalanine levels. Slightly increased incidence of schizoaffective psychosis } \\
\text { Slower reaction time. Reduction of test intelligence, especially spatial ability. }\end{array}$ \\
$\begin{array}{l}\text { Lipidoses: globoid cell } \\
\text { leucodystrophy (Krabbe); } \\
\text { metachromatic leucodystrophy: }\end{array}$ & $\begin{array}{l}\text { depression, emotional lability, 'inhibition, } \\
\text { Sandhoff, Niemann-Pick, }\end{array}$ \\
$\begin{array}{l}\text { Wolman disease } \\
\text { Microcephaly }\end{array}$ & $\begin{array}{l}\text { Normocephalic mental retardation in about } 1 / 3 \text { of obligate heterozygotes (parents of homozygous patients) in two series } \\
\text { from different parts of the world }\end{array}$ \\
Wilson's disease & EEG abnormalities and abnormal neurological signs
\end{tabular}


ance but personality and susceptibility to mental disease as well. If this is true, then systematic screening of psychiatric patients should lead to the discovery of many heterozygotes and possibly even homozygotes, which has, in fact, been found.

Metachromatic leucodystrophy, for example, is an autosomal recessive disease resulting from arylsulphatase A deficiency. The adult type of this disease has been known for some time to present sometimes as a psychiatric disease, primarily schizophrenia. ${ }^{25}$ In a recent study, Propping et al ${ }^{26}$ examined 2107 psychiatric patients, consecutive admissions to a psychiatric state hospital, for their arylsulphatase $\mathrm{A}$ activity and compared them with 519 normal controls. There were significantly more persons with enzyme levels in the heterozygote range than among the controls. Three patients were diagnosed as homozygotes. These results make it very likely that homozygotes as well as heterozygotes for this enzyme deficiency run an increased risk of becoming affected with some mental disease, for example, schizophrenia. Such increased liability is not confined to metachromatic leucodystrophy; some other hereditary diseases, such as intermittent porphyria, Huntington's chorea, and even sex chromosomal aneuploidies such as the XXY and XXX states, have been reported to present as schizophrenia. ${ }^{27}$ The 'disease' schizophrenia cannot be compared with monocausal diseases such as phenylketonuria or, for example, tuberculosis. ${ }^{8}$ As a phenomenological concept, it describes a certain group of reactions of the brain to a variety of stress factors. ${ }^{28}$ As pointed out, among others by Carter, ${ }^{10}$ search for one major biochemical cause is probably futile for this very reason. On the other hand, many homozygotes for arylsulphatase A deficiency, and the majority of heterozygotes, are not affected by any psychiatric disease. Some of them, as well as heterozygotes for other lipidoses, may display certain signs of neuronal irritability and emotional instability, as shown by Christomanou et $a l^{29} 30$ a few years ago. Hence, the genetic anomaly is not the only, and not even a sufficient, condition for the individual and social event classified as a psychiatric disease. It only causes an increased susceptibility. Other factors, genetic or environmental, must come together to cause the final breakdown.

This example gives us a clue as to what might be behind the description of a disease as 'polygenic' or, in a somewhat wider sense, 'multifactorial'. 10 11 Once this has been realised, such factors should be explored at various levels. As one example, we mentioned a screening study on psychiatric patients in comparison with normal controls. Like studies on heterozygotes, such screening studies appear to be fairly unsophisticated in outlook. However, they may lead to something quite interesting, provided that one knows what to look for.

\section{Studies on amino acids in mentally retarded patients: results for glutamate}

Another example. In the late 1950 s and early 1960 s, when I was still in Berlin, we compared amino acids in blood and urine of slightly mentally retarded children and appropriate controls. At that time amino acids were new and one hoped to discover new types of rare metabolic diseases with impressive excretion patterns. Unfortunately, we did not, but our study differed from other screening studies performed at the same time in that we applied a one dimensional paper chromatographic method which enabled not only the finding of extreme increases of certain amino acids, but allowed in addition a fairly good, semiquantitative assessment in the 'normal' or near-normal range. And here, we found something surprising: a high level of glutamate in a substantial fraction of patients and in some of their first degree relatives. $^{31-33}$

At that time, not much was known about the function of glutamate in the CNS, but there were reports that glutamate intake may enhance alertness and intellectual capacity. ${ }^{34}$ It was possible that some parents had increased it in order to improve the performance of their retarded children. The problem lingered in my mind for many years.

Since then, we have come to know much more. Glutamate has been identified as an important excitatory neurotransmitter. ${ }^{35} 36$ It can enter the brain from the blood through specific transport mechanisms ${ }^{37}{ }^{38}$; direct application to the brain of high doses leads to degeneration of certain neurones, probably by overstimulation ${ }^{38} 39$; and treatment of mice with the specific glutamate antagonist ATB (2-amino-4-phosphobutyric acid) decreases their ability for avoidance learning in the so-called shuttle box in a dose dependent manner. ${ }^{37}$

With so much more background knowledge, glutamate studies in mentally retarded patients just had to be taken up again. This time, however, we knew where to look. First, Sahai set up assays for all the important enzymes that could influence the blood glutamate level. Then, a patient sample from an institution for the mentally retarded was established, with appropriate control for chromosomal aberrations and exogenous factors. Moreover, all patients included in this study were carefully examined clinically, all amino acids were determined by column chromatography, and the important enzymes were controlled in the peripheral system. Again, there were a number of patients whose glutamate values were much higher than those of the 
controls. Moreover, patients with extremely high glutamate levels turned out to be more severely retarded, with IQ values below 50 . In addition, there was an overlap area where we found more patients than controls.

So far, we do not know for sure whether these patients are distinguished by other clinical features. However, studies on all the relevant enzymes, as well as on the pattern of amino acid levels in the blood, are now promising insights into more general functional principles of neuronal performance, especially as far as the neurotransmitter glutamate is concerned. Studies on glutamate and related amino acids in families of mentally retarded probands, as well as biochemical and behavioural studies in mice, will help to elucidate further this complicated set of problems.

The studies mentioned before on experimental animals showed a toxic effect to neurones of long term overstimulation with glutamate. ${ }^{40}$ More importantly, however, many recent results suggest a specific role of glutamate for establishment of long term memory. ${ }^{41}$

Possible hypotheses as to genetic variability based on our knowledge of structure and function of the CNS

This raises our discussions on research strategies to a new level. So far, our thinking has been somewhat simplistic, one could even say dull. We started with some well known observations, such as intelligence defects in patients with chromosomal aberrations or in hereditary metabolic diseases. Then, we extended our search to heterozygotes, who are mostly normal according to medical criteria. The theoretical rationale of such studies was a straightforward hypothesis based on the simple observation that enzyme activity in heterozygotes is about half that in normal homozygotes. As a final approach, we mentioned comparison of certain groups of patients with unaffected controls for a number of biochemical parameters, hoping for some fortuitous findings. But some of these studies not only revealed differences between patients and controls, but also suggested biological mechanisms for the anomalies found; in the glutamate case, overexcitation of neurones with negative influence on long term memory. This immediately raises new questions. When we want to find genetic variation that might influence brain function and behaviour, would it not be much sounder scientifically if we started at the opposite end? Can we derive hypotheses as to the levels at which genetic variability might influence behaviour, using the knowledge of neurobiology about structure and function of the brain? This approach would be, at least at the beginning, more speculative, but it would also be much more $\stackrel{\mathbb{\mathbb { T }}}{=}$ satisfactory intellectually. Most of us would prefer $\overrightarrow{\vec{*}}$ to make discoveries as a result of sophisticated thinking than by simple screening for several possible biological parameters in a random fashion.

At which levels of brain function could genetic $\vec{\nabla}$ variability exist and, very important, actually be $\varrho$ studied in humans?

(1) At the most elementary level, let us look at the $\overrightarrow{0}$ neurones and their connections, the synapses. They are characterised by specific neurotransmitters and $\vec{\omega}$ their enzymes. They are synthesised, stored, released, and degraded or reabsorbed. Moreover, neurotransmitters can act at the postsynapticin site only when bound to specific receptors. All these $\vec{\omega}$ elements are under genetic control; genetic $\vec{\sim}$ variability could exist. When you want to study it, $\mathcal{E}$ however, a difficulty common to all such studies in을 humans is encountered. Neurotransmitters and their enzymes have to be studied in the blood and it is 3 always a matter of conjecture to what degree $\frac{\text { ले }}{3}$ variability in the blood represents what goes on in $\supset$ the brain. Studies of neurotransmitters and their $\overrightarrow{0}$ enzymes in the major psychoses, hailed at the $\stackrel{\infty}{v}$ beginning with enthusiastic hope, have led to disappointment. ${ }^{42}$ Research workers who had beeno lured by the unquestionable success of treatment with psychotropic drugs into the hope for insight into basic mechanisms are at present largely dis- $\frac{}{\mathbb{D}}$ appointed. They realised that they have entangled $\stackrel{\Omega}{\vec{F}}$ themselves in a hopelss mess of secondary regula- $\overrightarrow{\overrightarrow{0}}$ tions, not to mention side effects of drugs. ${ }^{43-45} 3$ Possibly, research in this field started with the wrong neurotransmitters: catecholamines and their enzymes act not only in the brain, but in peripheral areas of the autonomic system as well. Moreover, mental diseases such as schizophrenia and affective disorders fluctuate periodically in the same subjects together with levels of neurotransmitters and theiro enzymes. This probably creates additional sources of complexity which we cannot cope with at present $?$ As mentioned before, mental retardation appears to be a simpler, and therefore better, anomaly to worke. with, since it is largely a permanent condition, not of state but a trait.

Meanwhile, we have learned that receptors, like enzymes, consist of specific proteins and may showe genetic variation. Animal receptor studies are verge fashionable and successful ${ }^{46}$ and the acetylcholine receptor has been studied extensively from the molecular point of view ${ }^{47}$ In humans, parameters of $\alpha$ adrenergic receptor binding have been studied in twins and genetic variability has been detected. $\frac{48}{\mathrm{D}}$ Receptor studies in humans might become one of the most promising fields in neurobiologically an $\mathbb{B}$ genetically founded behaviour genetics, provide $\bar{Q}$ 
that receptors or their genes can be studied in readily accessible material. So much for studies at the level of the single neurone.

(2) Another source of variation influencing behaviour might be found at the level of neuronal networks. These networks are formed largely during embryonic development. In mammals, and especially in humans, their formation continues right into childhood, depending on proper stimulation from the environment, a good example of the classical counterparts nature and nurture. It is known from studies on the mouse, especially its neurological variants, that neurones and their axons and dendrites find their proper places under the influence of cell type specific neuronal surface antigens, and mutations may lead to specific disturbances, ${ }^{49}$ another possible source of genetic variability that is bound to influence density and functional efficiency of neuronal networks. In humans, this field appeared to be completely unexplored until recently, but in a deletion in the short arm of chromosome 17 , which leads to a lissencephaly syndrome, pyramid cells were found turned upside down in frontal and occipital parts of the cortex. ${ }^{49 a}$

(3) Thirdly, at the macroscopic level of organisation, we find cooperation of the various functional subsystems of the brain that influence spontaneous activity, information processing, and action. For example, incoming stimuli are switched over in the reticular system of the brain, and often in the thalamus, before reaching the cortex where they are processed and influence the ways we feel and behave. This information processing is modulated by the rhythmic, spontaneous activity of neurones, singly and in groups, in several subsystems of the brain, a fertile field for neurophysiologists, since this activity is accompanied by electrical discharges and voltage oscillations ${ }^{50}$ Rhythmic activity in the living human brain can be studied in the electroencephalogram (EEG). The normal human EEG shows genetic variability ${ }^{51}$; studies on some hereditary variants point to differences in central information processing and thus in the way people feel and behave ${ }^{52-55}$ Three variants have mainly been studied: the low voltage EEG and the EEG with monomorphic alpha waves, counter types in that in one, the alpha activity is almost nil, while in the other, regular high amplitude alpha activity spreads over the entire surface of the head. Both are inherited in a simple autosomal dominant fashion and have a frequency of about $4 \%$ each in the normal population. Neurophysiological as well as psychological evidence is compatible with the hypothesis that modification and selective amplification of stimuli may be weak in the low voltage and strong in the monomorphic alpha type. In a third
EEG variant, in which alpha waves are mixed diffusely with faster frequencies in the beta range, and which appears to be polygenic in origin, results favour the explanation that information processing might be disturbed by influences from other parts of the brain.

This is not the place to go into this very specialised field in great detail. I only mention it to show that detailed analysis of genetic variations influencing mental performance and behaviour is possible not only at the DNA or biochemical level but, under certain favourable conditions, also at the phenotype level which can be assessed using methods from neurophysiology. ${ }^{56}$ However, this needs a combination of genetic and neurophysiological expertise which is very rare indeed. As mentioned repeatedly in this lecture, the growth of scientific knowledge does not follow logical rules; rather, science is an activity of groups of human beings and therefore its progress depends on the interests and expert knowledge present in these groups. It is hard to explain why there is surprisingly little overlap between groups interested in physiology, especially neurophysiology, and genetics. In my opinion, this is a drawback for the development of both fields. I personally happen to have some limited knowledge of EEGs and can therefore use it for genetic purposes. I simply do not know whether other methods in neurophysiology would lend themselves to genetic analysis, provided that somebody could combine expertise in the two fields.

Let me stress yet another point. With the genetic variants of the EEG, we have finally left the field of pathology and entered the 'normal' range. They satisfy Harry Harris's definition of a genetic polymorphism, but there are many other polymorphisms that can be studied at the protein level. ${ }^{11} 5758$ Occasionally, associations with behavioural traits have been described; results, however, are not very convincing. The reason is that nobody has any idea of a possible role of these proteins and cell surface antigens in brain function. Therefore, no specific, testable hypothesis as to the kind of possible associations can be put forward. Would it not be possible to look for protein polymorphisms for which a specific function in the brain is known? Recent progress in the analysis of genes at the DNA level ${ }^{11}$ also suggests the 'reverse genetic' approach, from gene to protein to basic function. Linkage studies of monogenic EEG variants with RFLPs, for example, should be possible and should help to characterise the genes involved. As mentioned in the beginning, orderly function of the brain depends on many different gene controlled systems. From this, one could conclude that, as a rule, genetic variation in the 'normal' range in one of these 
components will have only a small influence on brain function and behaviour. This also conforms to our traditional notion of polygenic inheritance. However, it might not always be true, since we know that there is a hierarchy of enzymes and proteins; variation in some biochemical mechanisms, for example, cofactor uptake, and even enzymes such as glutathione peroxidase, may influence function of several other systems (see the interesting, but very speculative ideas of Weiss ${ }^{59}$ ). Glutathione peroxidase activity, for example, has been shown to be inversely correlated with IQ in patients with trisomy $21 .^{60}$ It might possibly be worthwhile to look for this enzyme in normal subjects.

Let me summarise this part of my lecture. It was my intention to suggest approaches to neurobiologically founded human behaviour genetics not only by logical extension of approaches familiar to the geneticist but, in addition, by reviewing our knowledge of the hierarchical organisation of the human brain and looking for possible sources of variation. The evidence we encountered was scarce. We found a few scattered attempts but only occasional success. One could regard this as disappointing, but in my opinion it should rather be regarded as a challenge to use one's imagination in order to fill in this big white spot on the map of our genetic knowledge.

\section{Mutation and selection in the $\operatorname{mar}(\mathbf{X})$ syndrome}

Let us return to an area more familiar to the medical geneticist. I want to show you with one example how old and, in the opinion of some of us, outdated problems are coming back dressed in new clothes. You all know the marker (X) syndrome. ${ }^{61}$ In males, it is the second most common single genetic type of mental retardation with a prevalence of about 1 in 2000 to 1 in 2500 , the most common being Down's syndrome. According to a recent and well founded estimate, about $80 \%$ of male and $30 \%$ of female gene carriers are mentally retarded. This immediately raises the question: why is the condition so common despite the fact that male patients do not reproduce at all and reproduction of female patients is severely reduced? At first glance, the most obvious explanation seems to be an unusually high mutation rate. ${ }^{62}$ But to satisfy Haldane's equilibrium postulate, ${ }^{63}$ it should be about three times as high as the highest mutation rate estimate observed so far and, moreover, it should be confined entirely to male germ cells, since (almost?) no cases that could be traced back to fresh mutations in maternal germ cells have been observed. This is so unlikely that it calls for an alternative explanation. What about the $20 \%$ male and $70 \%$ female carriers who are not mentally $\stackrel{\vec{\Rightarrow}}{\vec{*}}$ retarded according to clinical criteria? It is true that $\stackrel{\vec{\sigma}}{\rightarrow}$ some of them, especially the male carriers, appearo to be quite 'normal'. But what about the females? At least among them, we should expect from the $\frac{\bar{\rho}}{\sigma}$ Lyon hypothesis a more continuous distribution of $\stackrel{\mathbb{\complement}}{\varrho}$ intellectual capabilities and, indeed, a pilot study on a limited series of 'normal' carrier females showed, $\rightarrow$ in most cases, IQ scores between 70 and 90.64

A negative correlation between intellectual per- $\overrightarrow{\vec{\omega}}$ formance in the normal or slightly subnormal range, $\stackrel{\sigma}{\sigma}$ position in society, and reproduction has been documented extensively in industrial countries, at

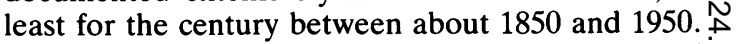
This has been a matter of concern for the old $\omega$ eugenicists and has often been discussed by the $\vec{N}$ older generation of human geneticists, including ${ }_{0}^{6}$ Carter in his book Human heredity, ${ }^{1}$ and also Penrose. ${ }^{65}$ Penrose, for example, explained that $\mathrm{a}_{\vec{z}}$ higher reproductive rate in persons with borderline intelligence need not necessarily lead to a con- $\widehat{\widehat{O}}$ tinuous increase of their genes in the population, $\vec{P}$ because in the same families a certain proportion of $\infty$ severely retarded subjects would be expected to. occur who will not reproduce at all. In other words, he postulated genetic equilibrium between a selective disadvantage of genes in severely mentally retarded persons and an advantage in intellectually borderline persons in the same families. In my® opinion, this type of equilibrium, in combination $\overrightarrow{\vec{F}}$ with a moderately high mutation rate, could offer a plausible explanation for the unusually high prevalence of the $\operatorname{mar}(\mathrm{X})$ syndrome. ${ }^{66}$ Recently, we haveo tested the mutation hypothesis in a cooperative statistical study of comprehensive family data from several European countries. ${ }^{67}$ The result is not:compatible with the assumption that the mutation?. rate is sufficient to explain the high prevalence of this syndrome in our population. Since other alternatives such as segregation distortion have beeno excluded before, ${ }^{62}$ there remains hardly any other $>$ explanation but a transitory selective advantage ino addition to a fairly, but not extraordinarily, high mutation rate. ${ }^{*}$

With this old problem and its old-fashioned butn plausible solution, let me finish this lecture on research strategies in human behaviour genetics. It might help us to remember, and to learn from pioneers of our field such as Cedric Carter, that wer should be eager to find new ways into the future, butes?

${ }^{*}$ I am aware that recently the hypothesis has been proposed by two groups ${ }^{68} 60$ that the mutational events involved in the mar(X) syndrome might be of 울 complex nature and that clinically unaffected male carriers might carry a kinf of premutation. This, however, appears not to affect the population genetif్ argument on mutation and selection. Moreover, it has been shown recentlp that the incomplete and variable phenotypic manifestation might also be 
in order to be successful, it might be useful sometimes to read what our scientific forefathers have written, to follow their ways of thinking, and to be aware of the scientific tradition of our field, human genetics.

\section{References}

I Carter CO. Human heredity. Harmondsworth: Penguin, 1962. Galton F. Hereditary talent and character. Macmillan's Magazine 1865:12:157.

3 French-Anderson W. Prospects for human gene therapy. Science 1984;226:401-9.

4 Fleck L. Entstehung und Entwicklung einer wissenschaftlichen Tatsache. Basel: Schwabe, 1935.

5 Kuhn TS. The structure of scientific revolutions. Chicago: University of Chicago Press, 1962.

6 Mendel JG. Versuche über Pflanzenhybriden. Verhandlungen des Naturforschenden Vereins, Brünn, 1865.

7 Falk R. The gene in search of an identity. Hum Genet 1984:68:195-204.

* Vogel F. Die Bedcutung der Humangenetik für eine Theorie der Krankheit. Verh Dtsch Ges Pathol 1982;66:1-15.

4 Galton F. The history of twins as a criterion of the relative powers of nature and nurture. J Anthropol Inst 1876.

11. Carter CO. Genetics of common disorders. Br Med Bull 1969:25:52-7.

1 Vogel F. Motulsky AG. Human genetics. Problems and approaches. 2nd ed. Berlin: Springer, 1986.

12 Jensen AR. How much can we boost IQ and scholastic achievement? Harvard Educ Rev 1969:39:1-123.

13 Jensen AR. Educability and group differences. London: Methuen, 1973.

14 Eysenck HJ, ed. A model for intelligence. Berlin: Springer, 1982.

15 Kamin IJ. The science and politics of $I Q$. Potomac: Erlbaum, 1974.

16 Lehrl S. Subjektives Zeitquant als missing link zwischen Intelligenzpsychologie und Neurophysiologie. Empirische Belege für die zeitliche Übereinstimmung vom subjektiven Zeitquant und einem Intelligenzindikator in evozierten Potentialen. Grundlagenstud Kybern Geisteswiss 1980;21:107-16.

17 Jensen AA. Munro E. Reaction time, movement time and intelligence. Intelligence 1979:3:121-76.

is Ruchalla E, Schalt E, Vogel F. Relations between mental performance and reaction time: new aspects of an old problem. Intelligence 1985:9:189-205.

19 Gulotta F, Rehder H, Gropp A. Descriptive neuropathology of chromosomal disorders in man. Hum Genet 1981:57:337-44.

21) McKusick VA. Mendelian inheritance in man. 7th ed. Baltimore: Johns Hopkins University Press. 1986.

21 Stanbury JB. Wyngaarden JB. Fredrickson DS, Goldstein JL, Brown MS. eds The metabolic basis of inherited disease. 5th ed. New York: McGraw-Hill, 1983.

22 Vogel F. Relevant deviations in heterozygotes of autosomal recessive diseases. Clin Genet 1984:25:381-415.

23 Vogel F. Phenotypic deviations in heterozygotes of phenylketonuria (PKU). In: Berg K, ed. Medical genetics, past, present, future. New York: Alan R Liss, 1985:337-49.

24 Quazi RH, Reed TE. A possible major contribution to mental retardation in the general population by the gene for microcephaly. Clin Genet 1975:7:85-90.

25 Propping P. Friedl W. Huschka M, et al. The influence of low arylsulfatase $A$ activity on neuropsychiatric morbidity: a largescale screening in patients. Hum Genet (in press).

26 Propping P. Friedl W. Monogenic discases presenting with psychiatric symptoms: clues to genetic heterogeneity. Proc IVth
World Congress of Biological Psychiatry, September 1985 , Philadelphia (in press).

27 Propping P. Genetic disorders presenting as 'schizophrenia'. Karl Bonhoeffer's early view of the psychoses in the light of medical genetics. Hum Genet 1983;65:1-10.

2x Vogel F, Propping P. Genetic variability and its influence on the risk to schizophrenia. In: Theoretical problems of modern psychiatry. Basel: Sandoz, 1984:59-73.

29 Christomanou H, Martinius J, Jaffé S, Betke K, Förster C. Biochemical, psychometric and neurophysiological studies in heterozygotes for various lipidoses. Hum Genet 1980;55:10310 .

30) Christomanou H, Jaffé S, Martinius J, Cap C, Betke K. Biochemical, genetic, psychometric and neuropsychological studies in heterozygotes of a family with globoid cell leukodystrophy (Krabbe's disease). Hum Genet 1981;58:179-83.

31 Hirsch W, Mex A, Vogel F. Quantitative Abweichungen am Rande der Norm in den freien Aminosäuren von Serum und Urin bei schwaschsinnigen Kindern. Monatsschr Kinderheilkd 1963;111:344-53.

32 Mex A, Hirsch W, Vogel F. Untersuchungen an den Aminosäuren im Serum schwachsinniger und gesunder Kinder mit Hilfe der Säulenchromatographie. Monatsschr Kinderheilkd 1963:111:421-8.

33 Hirsch W. Mex A. Vogel F. Metabolic traits in mentally retarded children as compared with normal populations: monoaminodicarboxylic acids and their half amides and total amino acids. J Ment Defic Res 1969;13:130-42.

34 Vogel W, Broverman DM, Draguns GJ, Klaeber EL. The role of glutamic acid in cognitive behavior. Psychol Bull 1966;56:367-82.

35 Fonnum F. Glutamate: a neurotransmitter in the mammalian brain. J Neurochem 1984;42:1-11.

36 di Chiara G, Gessa GL, eds. Glutamate as a neurotransmitter. New York: Raven, 1981

37 Sahai S, Buselmaier W, Brussman A. 2-amino-4phosphonobutyric acid selectively blocks two-way avoidance learning in the mouse. Neuroscience Letters 1985;56:137-42.

38 Oldendorf WH, Szabo J. Amino acid assignment to one of their blood amino acid carriers. Am J Physiol 1976;230:94-8.

34 Olney JW, De Gubareff T. Glutamate neurotoxicity and Huntington's chorea. Nature 1978;271:557-9.

4) Filer LJ, Garattini S, Kare MR, Reynolds WA, Wurtman RJ. Glutamic acid: advances in biochemistry and physiology. New York: Raven, 1978.

${ }^{41}$ Lynch G, Baudry M. The biochemistry of memory: a new and specific hypothesis. Science 1984;224:1057-63.

42 Gershon ES, Targum SD, Kessler LR, Mazure CM, Bunney WE. Genetic studies and biologic strategies in the affective disorders. Prog Med Genet 1978;11:101-6.

43 Maubach M, Diebold K, Friedl W, Propping M. MAOAktivität in Thrombocyten von affektpsychotischen Patienten und ihren Verwandten ersten Grades. In: Beckmann $\mathrm{H}$, ed. Biologische Psychiatrie. Stuttgart: Thieme Verlag, 1982:182-8.

${ }^{44}$ Vogel F. Propping P. Ist unser Schicksal mitgeboren? Berlin: Severin und Siedler, 1981.

45 Propping P. Friedl W. Platelet MAO activity and high risk for psychopathology in a German population. Mod Probl Pharmacopsychiatry 1983:19:304-14.

t6 Friedl W, Hebebrand J, Lentes KU. Propping P. Genetic approaches in psychobiology at the receptor level. Proc IVth World Congress of Biological Psychiatry. September 1985, Philadelphia (in press).

47 Changeux JP, Klarsfeld A, Heidmann T. The acetylcholine receptor and molecular models for short and long term learning. Unpublished paper from the Dahlem Conference, Berlin, December 1985.

48 Propping P. Friedl W. Genetic control of adrenergic receptors on human platelets. A twin study. Hum Genet 1983;64:105-9. 
49 Caviness VS, Rakic P. Mechanisms of cortical development: a view from mutations in mice. Ann Rev Neurosci 1978;1:297326.

49a Bordarier C, Robain O, Rethoré O, Dulac O, Dhelemes C. Inverted neurons in agyria - a Golgi study of a case with abnormal chromosome 17. Hum Genet 1986;73:374-8.

50 Andersen P, Andersson SA. Physiological basis of the alpha rhythm. New York: Appleton-Century Crofts, 1968.

s1 Vogel F. The genetic basis of the normal human electroencephalogram (EEG). Hum Genet 1970;10:91-114.

52 Vogel F, Schalt E, Krüger J, Propping P. The electroencephalogram (EEG) as a research tool in human behaviour genetics: psychological examinations in healthy males with various inherited EEG variants. I Rationale of the study; material; methods; heritability of test parameters. Hum Genet 1979;47:145.

53 Vogel F, Schalt E, Krüger J. II Results. Hum Genet 1979;47: 47-80.

54 Vogel F, Schalt E. III Interpretation of the results. Hum Genet 1979;47:81-111

55 Vogel J, Krüger J, Höpp HP, Schalt E, Schnobel R. Visually and auditory evoked EEG potentials in carriers of four hereditary EEG variants. Hum Neurobiol 1986;5:49-58.

56 Report of the IVth World Congress of Biological Psychiatry, Philadephia, 1985. (in press).

57 Prokop O, Göhler W. Die menschlichen Blutgruppen. 5th ed. Stuttgart: Fischer Verlag, 1986.

58 Harris H. The principles of human biochemical genetics. 4th ed. Amsterdam: North Holland, 1980.

59 Weiss V. From the genetics of memory span and mental speed toward the quantum mechanics of intelligence (in press).

6) Sinet PM, Lejeune J, Jerome H. Trisomy 21 (Down's syndrome), glutathione peroxidase, hexose monophosphate shunt and IQ. Life Sci 1979;24:29-33.

61 Opitz JM, Sutherland GR, eds. Conference report. International workshop on the fragile $\mathrm{X}$ and $\mathrm{X}$-linked mental retardation. Am J Med Genet 1984;17:5-385.
62 Sherman, SL, Morton NE, Jacobs PA, Turner G. The marker" (X) syndrome: a cytogenetic and genetic analysis. Ann Hum Genet 1984;48:21-37.

63 Haldane JBS. The rate of spontaneous mutation of a human? gene. J Genet 1935;31:317-26.

64 Paul J, Froster-Iskenius U, Moje W, Schwinger E. Heterozy-ब gous female carriers of the marker-X-chromosome: IQ estima- $\overline{\mathbb{Q}}$ tion and replication status of $\mathrm{fra}(\mathrm{X})(\mathrm{q})$. Hum Genet 1984 ;0 66:344-6.

65 Penrose LS. Outline of human genetics. 2nd ed. London: Heinemann, 1963.

66 Vogel F. Mutation and selection in the marker $(\mathrm{X})$ syndrome.Ann Hum Genet 1984;48:327-32.

67 Vogel F, Krüger J, Brøndum-Nielsen K, et al. Recurrenţ mutation pressure does not explain the prevalence of the marker (X) syndrome. Hum Genet 1985;71:1-6.

68 Pembrey ME, Winter RM, Davies KE. A premutation thain generates a defect at crossing over explains the inheritance of fragile X mental retardation. Am J Med Genet 1985;21:709-17:

69 Sherman SL, Jacobs PA, Morton NE, et al. Further segregation of the fragile $\mathrm{X}$ syndrome with special reference to transmitting males. Hum Genet 1985;69:289-99.

70 Steinbach P. Mental impairment in Martin-Bell syndrome is probably determined by interaction of several genes: simple explanation of phenotypic differences between unaffected anक् affected males with the same X chromosome. Hum Genȩ̄ 1986;72:248-52.

Correspondence and requests for reprints to Profes-O sor $F$ Vogel, Institut für Anthropologie und Humangenetik, University of Heidelberg, $I \mathrm{~m}_{\mathrm{D}}$ Neuenheimer Feld 328, D-6900 Heidelberg, Fed-응 eral Republic of Germany. 